\title{
Análisis financiero en las empresas comerciales \\ de Ecuador
}

\author{
Molina , Luisa \\ Oña, Jessica \\ Tipán, Mayra \\ Topa, Sharon \\ Universidad de las Fuerzas Armadas ESPE, Latacunga, Ecuador \\ ljmolina4@espe.edu.ec
}

Recibido: 8 enero 2018
Aprobado: 29 enero 2018

\section{Resumen:}

El análisis financiero es herramienta indispensable en las organizaciones sin importar el tipo de actividad que desarrollen, puesto que mediante el cálculo de los indicadores financieros se puede conocer la situación real en la que se encuentra la entidad además es útil para tomar decisiones que permitan el cumplimiento de los objetivos de manera eficaz y eficiente. El objetivo de la investigación es analizar la situación financiera del sector comercial del Ecuador en relación con el análisis de los indicadores financieros, realizado a partir de la consolidación de estados financieros a través de una muestra de ciertas entidades comerciales del país.

La metodología aplicada dentro del presente trabajo es descriptiva puesto que se llevara a cabo un análisis de las características que poseen los diagnósticos financieros y los diferentes indicadores además se efectuará un muestreo por cuotas en el cual se escogió un número de datos concretos de estudio que cumplan con los requerimientos, puesto que la información de las entidades comerciales subidas a la Superintendencia de Compañías son confidenciales y poseen cierto grado de dificultad de acceso.

Palabras claves: Análisis Financiero, Indicadores Financieros, Empresas comerciales 


\title{
Financial analysis in the comercial companies of Ecuador
}

\begin{abstract}
:
The financial analysis is an indispensable tool in the organizations without importing the type of activity that they develop, since by means of the calculation of the financial indicators it is possible to know the royal situation in the one that is the entity in addition it is useful to take decisions that allow the fulfillment of the aims of an effective and efficient way. The aim of the investigation is to analyze the financial situation of the commercial sector of the Ecuador in relation with the analysis of the financial indicators, realized from the consolidation of financial statements across a sample of certain commercial entities of the country.

The methodology applied inside the present work is descriptive since there was carried out an analysis of the characteristics that possess the financial diagnoses and the different indicators in addition a sampling will be effected by quotas in which there was chosen a number of concrete information of study that expire with the requirements, since the information of the commercial entities raised to the Superintendence of Companies they are confidential and possess certain degree of difficulty of access.
\end{abstract}

Key words: Financial Analysis, Financial Indicators, Business ventures

\section{Introducción}

El análisis financiero es indispensable en cualquier tipo de empresa sea comercial, industrial, de servicios, entre otros, este análisis permite conocer la situación real y actual de la información económica y financiera. En este estudio se aplicará un diagnóstico financiero a través de indicadores de liquidez, actividad, endeudamiento y rentabilidad con relación a los estados financieros de las empresas del sector comercial mediante una consolidación.

Además, el análisis financiero es clave para los gerentes y administradores que son los encargados de tomar decisiones importantes para el desarrollo de la empresa, debido a que este análisis permite conocer si se está trabajando de modo óptimo y así alcanzar las metas de la entidad. Para realizar el diagnóstico financiero y cálculo de indicadores financieros se debe contar con el Estado de Situación Financiera y el Estado de Resultados. Para el presente trabajo de investigación se realiza un análisis financiero de una determinada muestra de empresas comerciales del Ecuador.

\section{Diagnóstico financiero}

El objetivo básico financiero de toda empresa según manifiesta Bravo (2017) “es maximizar el valor de la empresa y para lograrlo se deben tomar decisiones bajo una perspectiva de largo plazo buscando siempre la permanencia y el crecimiento en el mercado" (p.67). De acuerdo con el autor el objetivo financiero es 
maximizar el valor de la empresa por tal razón es muy importante realizar un análisis financiero y cálculo de los indicadores financieros dentro de las entidades así se podrá conocer la situación real de la organización y tomar decisiones correctas a favor de la misma, para así cumplir con dicho objetivo financiero.

Por diagnóstico financiero o análisis financiero según manifiesta Quizhpe (2013) “es el estudio que se hace de la información que proporciona la contabilidad y de toda la demás información disponible para tratar de determinar la situación financiera de la empresa o de un sector específico de ésta" (p. 24). Es decir, permite ver la composición de la empresa o de un sector dentro del análisis financiero existe dos tipos de análisis el vertical y el horizontal mediante los cuales se puede interpretar los resultados obtenidos dentro de la organización y así poder tomar decisiones correctas que ayude a la toma de decisiones.

\section{Indicadores financieros}

De acuerdo con Reyes, Cadena \& León (2014) “es un análisis de razones evalúa el rendimiento de la empresa mediante métodos de cálculo e interpretación de razones financieras. La información básica para el análisis de razones se obtiene del estado de resultados y del balance general de la empresa, es importante para sus accionistas, sus acreedores y para la propia gerencia" (p. 25).

\section{Indicadores de liquidez}

Permite analizar si la empresa puede cumplir sus obligaciones a corto plazo dentro de los indicadores de liquidez se encuentra la razón corriente, prueba acida y el capital neto de trabajo

\section{Razón corriente}

Según manifiesta Quizhpe (2013) "La razón corriente es uno de los indicadores financieros que permite determinar el índice de liquidez de una empresa, indica la capacidad que tiene la empresa para cumplir con sus obligaciones financieras, deudas o pasivos a corto plazo" (p. 30). Para determinar la razón corriente se toma el activo corriente y se divide por el pasivo corriente.

Razón Corriente $=($ Activo Corriente) $/($ Pasivo Corriente)

En base al autor la razón corriente es el que permite verificar si la empresa puede cubrir sus pasivos corrientes con sus activos corrientes considerando los inventarios. 


\section{Prueba ácida}

Según Barrios, Huamán, \& Rodríguez (2016) Menciona que "la prueba acida es una medición más exigente por cuanto no se consideran las existencias o inventarios, ya que tienen menor liquidez que los otros componentes del activo corriente" (p. 25). De esta manera se podrá identificar la solvencia que la empresa posee por cada dólar, es muy importante tomar los valores de la prueba acida ya que esta muestra con mayor veracidad la realidad de las empresas. Para realizar el cálculo se muestra la fórmula de aplicación:

Prueba ácida $=$ (Activo Corriente-Inventarios) $/$ (Pasivo Corriente)

Esta fórmula ayudara a determinas la situación real de cualquier empresa en relación a la solvencia de corto plazo.

\section{Capital neto de trabajo}

Castelo \& Anchundia (2016) expone que "La razón del capital neto de trabajo la obtenemos del activo corriente menos el pasivo corriente, lo cual es la representación del monto de recursos que la compañía necesita para cubrir sus obligaciones contando con un capital neto de trabajo" (p. 72). Ayuda a identificar con mayor claridad las necesidades que tiene una empresa para desarrollar con éxito las operaciones económicas. El autor menciona la siguiente fórmula para su cálculo:

\section{Activo Corriente - Pasivo Corriente}

Esta fórmula ayudara a determinas cual es el capital real de cualquier empresa, se expresa en número de veces.

\section{Indicadores de actividad}

Álvarez \& Morocho(2013) menciona "los indicadores de actividad son aquello que miden que tan rápido diversas cuentas se convierten en ventas o efectivo, es decir entradas o salidas" (p. 35). Analizan la velocidad con la que diferentes cuentas se transforman en efectivo, como por ejemplo la mercadería de una empresa.

\section{Rotación de cartera}

Para Pérez (2014) expone "la rotación de cartera es el indicador que establece el número de veces que las cuentas por cobrar giran, en promedio de un periodo determinado de tiempo, que generalmente es un año" (p. 32). Este indica cuantas veces ha girado la cuenta por cobrar en un determinado periodo de tiempo. El autor redacta la fórmula que se debe aplicar:

Rotación de Cartera $=($ Cuentas por Cobrar 
Promedio*365 días )/(Ventas a crédito)

Esta fórmula ayudara a determinas cuantas veces giran las cuentas por pagar, se expresa en número de días.

\section{Rotación de inventario}

Pérez (2014) menciona que la rotación de inventario es un "indicador que mide cuanto tiempo le toma a la empresa rotar sus inventarios. Los inventarios son recursos que la empresa tiene inmovilizados y que representan un costo de oportunidad (p. 32). Ayuda a identificar el tiempo que le toma a la empresa rotar los inventarios, con este análisis se puede tomar decisiones adecuadas. El autor redacta la fórmula que se debe aplicar:

Rotación de inventario $=$ (Inventario Promedio*365 días)/(Costo de Mercancía Vnedida)

Esta fórmula ayudara a determinar con mayor claridad el movimiento que tienen los inventarios en la empresa, se expresa en número de días.

\section{Rotación de proveedores}

Cárdenas (2016) afirma "la rotación de proveedores es aquella que mide el número de veces que las cuentas por pagar a proveedores rotan durante un período de tiempo determinado, es decir el número de veces en que tales cuentas por pagar se cancelan usando recursos líquidos de la empresa" (p. 37). Ayuda a identificar cuantas veces la cuenta de proveedores gira durante un determinado periodo de tiempo. El autor redacta la fórmula que se debe aplicar:

Rotación de proveedores $=($ Cuentas por Pagar Promedio x 360 días)/(Compras Totales)

Esta fórmula ayudara a determinar con mayor claridad el movimiento que tiene la cuenta proveedores en la empresa, se expresa en número de días.

\section{Ciclo efectivo}

Castillo (2012) menciona "el ciclo de efectivo es aquel en el que se centra en el plazo de tiempo que corre desde que la compañía hace pagos hasta que recibe los flujos de entrada de efectivo" (p. 19). Este indica el plazo en el que una cantidad de dinero invertida en los activos corrientes es recuperada. El autor redacta la fórmula que se debe aplicar:

(Rotación de Cartera+Rotación de Inventarios totales)-Rotación de Proveedores

Esta fórmula ayudara a determinar con mayor claridad el tiempo que tarda en recuperarse 
una cantidad invertida, se expresa en número de días.

\section{Rotación del activo}

Cárdenas (2016) expone que la rotación de activos totales es aquella que "muestra la capacidad de una empresa para la utilización de sus activos totales en la obtención de ingresos, es decir, la eficiencia en el manejo de los activos para generar más ventas (p. 36). Muestra con claridad el desempeño de la empresa al momento de utilizar los activos de la empresa para generar ingresos. El autor menciona la fórmula que se debe aplicar:

Rotación de activo $=$ Ventas $/($ Activos Totales $)$

Esta fórmula ayudara a determinar con mayor claridad el movimiento que tienen los activos de la empresa, se expresa en número de veces.

\section{Indicadores de rentabilidad}

Según De La Hoz Suárez, B., Ferrer, M. A., \& De La Hoz Suárez, A. (2008) Los indicadores referentes a rentabilidad, tratan de evaluar la cantidad de utilidades obtenidas con respecto a la inversión que las originó, ya sea considerando en su cálculo el activo total o el capital contable. Se puede decir entonces que es necesario prestar atención al análisis de la rentabilidad porque las empresas para poder sobrevivir necesitan producir utilidades al final de un ejercicio económico, ya que sin ella no podrán atraer capital externo y continuar eficientemente sus operaciones normales (p.1).

Los indicadores de rentabilidad son aquellos que permite ver la forma de como optimizar costos, gastos de la mejor manera, así como la habilidad de generar utilidades durante el ejercicio contable permitiendo de esta manera un funcionamiento adecuado en las operaciones de la empresa.

\section{Margen bruto}

El margen bruto es la diferencia entre el precio de venta (sin IVA) de un bien o servicio y el precio de compra de ese mismo producto. Este margen bruto, que suele ser unitario, es un margen de beneficio antes de impuestos. Se

expresa en unidades monetarias/unidad vendida. Para Ciappa (2005) "Beneficio bruto: Es el margen obtenido por la diferencia entre el precio de venta del producto/servicio y su coste. Es el beneficio que reporta la actividad básica de la empresa. El margen bruto, por tanto, mide la rentabilidad derivada de la venta del servicio/ 
producto" (p.43).

Margen bruto $=($ Beneficio bruto $) /$ Ventas

Considerando lo establecido anteriormente el margen bruto constituye la utilidad únicamente descontando de los ingresos por ventas los costos de venta, es decir sin tomar en consideración los impuestos, constituyéndose como una utilidad básica para la empresa.

\section{Margen operacional}

El margen operativo mide la rentabilidad de la empresa como una parte de sus ventas totales, una fórmula que da una visión amplia del desempeño de la empresa, pero que no está exento de limitaciones.

Para De La Hoz Suárez, B., Ferrer, M. A., \& De La Hoz Suárez, A. (2008)

Representa lo que puede ser llamado utilidades puras, ganadas por la empresa entre cada unidad monetaria de ventas. Las utilidades de operación son puras en el sentido de que ignoran cargos financieros o gubernamentales (intereses o impuestos), y miden solo las utilidades obtenidas en las operaciones" (p.27)

Margen operacional de Utilidad $=$ (Utilidad Operacional $) /($ ventas netas $)$
En base al parágrafo anterior margen operacional constituye la utilidad descontando de los ingresos por ventas los costos de venta y además tomando en cuenta los impuestos, constituyéndose como una utilidad un poco más cerca de la realidad para la entidad.

\section{Margen neto}

La utilidad del margen neto está en que refleja la capacidad de la organización para convertir los ingresos que recibe en beneficios. En otras palabras, permite saber si se está realizando un eficiente control de costes.

Como menciona Fontalvo Herrera, T., Mendoza Mendoza, A., \& Morelos Gómez, J. (2011) establece

Es un indicador de rentabilidad que se define como la utilidad neta sobre las ventas netas. La utilidad neta es igual a las ventas netas menos el costo de ventas, menos los gastos operacionales, menos la provisión para impuesto de renta, más otros ingresos menos otros gastos. Esta razón por sí sola no refleja la rentabilidad del negocio. (p.1)

Margen neto de utilidad $=($ Utilidad neta $) /($ Ventas Netas)

En concordancia con lo mencionado el 
margen neto de la utilidad aquel beneficio real que obtiene la empresa en el giro de negocio en la cual se descuentan de los ingresos por ventas los costos de venta, gastos operativos, gastos financieros, gastos de administración, así como los impuestos, provisiones, reservas y participaciones de los empleados.

\section{Rendimiento del patrimonio (Roe)}

Pineda, F., \& Piñeros-Gordo, J. H. (2009) menciona que:

Es un indicador ideal para que a partir de allí se establezcan los umbrales de los demás indicadores financieros, pues se reduce el grado de subjetividad al escoger los estados de alerta amarilla y roja. El primero supone que el aumento anual de por lo menos del $10 \%$ del patrimonio inicial antes de dividendos y capitalizaciones. El segundo supone que una entidad no tiene la capacidad de generar riqueza y en este caso su rentabilidad patrimonial sería inferior al $0 \%$ real. (p.10)

$$
\mathrm{ROE}=(\text { beneficio neto }) /(\text { fondos propios })
$$

El ROE es un indicador muy utilizado para la comparación de la rentabilidad de empresas del mismo sector; sin embargo, la comparación de empresas de diferentes sectores puede llevar a conclusiones erróneas puesto que el rendimiento de los capitales difiere en función de muchos aspectos que son propios de sectores diferentes.

\section{Rendimiento del activo (Roa)}

Tárraga, A. J. (2011) manifiesta que este indicador "tratará de disminuir el capital de trabajo mejorando el manejo de los inventarios o mejorar el efectivo o las cuentas por cobrar, o también puede reducir los activos fijos mediante franquicias o subcontratando la producción o mejorando la productividad" (p.37).

En relación con el autor el ROA es uno de los indicadores financieros más importantes y empleados actualmente por todas las empresas para establecer su rentabilidad es el ROA, el cual, consiste en la relación entre el beneficio obtenido en un determinado período y los activos globales de una empresa

$\mathrm{ROA}=($ EBIT-Impuestos $) /($ Activos totales $)=$ (Beneficio neto+Intereses)/(Activos totales )

\section{Ebitda}

Méndez, C. A. B. (2007) lo define como "un indicador de desempeño operacional que permite tener una idea acerca de la parte de los ingresos generados por las operaciones de 
la empresa que se destinaran a cubrir el costo0 de capital asociado a la generación de bienes o servicios de la empresa”. (p.44)

\section{Margen EBITDA $=$ EBITDA/Ventas}

Enrelación a lo mencionado anteriormente el EBITDA es una utilidad depurada es decir que no considera los impuestos, intereses, depreciaciones y amortizaciones, lo que permite comparar la rentabilidad del rendimiento operativo de las empresas.

\section{Indicadores de endeudamiento}

Como menciona Castaño \& Giraldo (2012)

Los indicadores de endeudamiento tienen por objeto medir en qué grado y de qué forma participan los acreedores dentro del financiamiento de la empresa. Indirectamente muestra el grado de riesgo que corren dichos acreedores. Desde el punto de vista de la empresa, los indicadores de endeudamiento sirven para observar la utilización de los recursos externos, es decir con el dinero de quién se está trabajando; y desde el punto de vista del acreedor le permite determinar hasta donde puede otorgar crédito a la empresa (p.2).

Considerando al autor se puede establecer que los indicadores de endeudamiento son aquellos que nos permiten generar políticas de financiamientos mediante préstamos permitiendo la adquisición de recursos necesarios para el funcionamiento adecuado de las operaciones y actividades del negocio.

\section{Nivel de endeudamiento}

Para Castaño \& Giraldo (2012)

Los indicadores de endeudamiento tienen por objeto medir en qué grado y de qué forma participan los acreedores dentro del financiamiento de la empresa. Indirectamente muestra el grado de riesgo que corren dichos acreedores. Desde el punto de vista de la empresa, los indicadores de endeudamiento sirven para observar la utilización de los recursos externos, es decir con el dinero de quién se está trabajando; y desde el punto de vista del acreedor le permite determinar hasta donde puede otorgar crédito a la empresa (p.2).

Nivel de Endeudamiento $=($ Total pasivo $) /($ Total activo)

Con base a lo anterior el nivel de endeudamiento es el que ayuda a verificar la forma en que se distribuye la participación de los dueños de la entidad considerando los acreedores 
y los accionistas, de esta manera poder tomar decisiones cuando los accionistas estén perdiendo el control de las actividades de la empresa.

\section{Concentración de los pasivos a corto} plazo

Según manifiesta Castaño \& Giraldo (2012) "este indicador permite mostrar en donde se encuentran concentrados los pasivos, si en el corto o en el largo plazo y así muestra la estructura de capital de una empresa. La concentración se mide mostrando la participación de los pasivos corrientes y de los pasivos no corrientes en el total de pasivos" (p.3).

Concentración de los pasivos a corto plazo= (Pasivo corriente)/(Pasivo Total)

En relación al párrafo anterior se puede decir que la concentración de los pasivos a corto plazo nos permite identificar cuanto es lo que la empresa adeuda a corto plazo dentro de sus pasivos totales lo que es beneficioso porque se evitan retrasos en el cumplimiento de las obligaciones corrientes.

\section{Endeudamiento financiero}

Castaño \& Giraldo (2012) menciona que este indicador

Establece el porcentaje de participación de todos los acreedores dentro de la empresa, considerando a los acreedores como todos los entes externos a la empresa y a los cuales ella adeuda o tiene obligaciones independientemente del concepto que lo genere: comercial, laboral, de impuestos, financiero o cualquier otro (p.16).

Endeudamiento Financiero $=\quad($ Obligaciones Financieras promedio )/Ventas

Considerando al autor se establece que el endeudamiento financiero contribuye al conocimiento de cómo favorecen las ventas a la cancelación de obligaciones financieras.

\section{Impacto de carga financiera}

Para Garzón (2017) este indicador

Indica el porcentaje que representan los gastos financieros respecto a las ventas durante el mismo período. Es necesario considerar este resultado ya que el margen de carga financiera es máximo del 10\% de las ventas y en ningún caso es conveniente que lo supere, la empresa podría estar funcionando para pagar sólo sus gastos financieros, un nivel de carga financiera aceptable es de $5 \%$ a $8 \%$. (p.30)

Impacto de la carga financiera $=$ (Gastos financieros $) /($ ventas )

Molina, Luisa; Oña, Jessica; Tipán, Mayra \& Topa, Sharon 
De acuerdo con el auto se dice que el impacto de carga financiera indica en qué grado de porcentaje las ventas ayudan al pago de intereses de obligaciones financieras conocidas como gastos financieros.

\section{Cobertura de intereses I}

Aponte \& Cuello (2018) manifiestan que este indicador "indica la incidencia que tienen los gastos financieros sobre las utilidades de la empresa, y si la misma dispone de la suficiente capacidad en términos de utilidad operacional para pagar intereses superiores a los actuales". (p.40)

Cobertura de intereses $=($ Utilidad antes de intereses e impuestos )/Intereses

Según manifiesta el autor la cobertura de intereses establece la incidencia que tienen los gastos financieros sobre las utilidades operacionales de la empresa lo que permite analizar la capacidad de endeudamiento.

\section{Resultados}

\section{Tabla 1}

Analisis vertical Estado de resultados

Estado de resultados año 2017 del sector comercial

Total consolidado

Análisis vertical

\begin{tabular}{|c|c|c|}
\hline $\begin{array}{l}\text { Ventas netas locales de bienes gravadas con tarifa diferente de } 0 \% \text { de } \\
\text { IVA }\end{array}$ & $8.817 .838,21$ & 31,86 \\
\hline $\begin{array}{l}\text { Ventas netas locales gravadas con tarifa diferente de } 0 \% \text { de IVA o exen- } \\
\text { tas del IVA }\end{array}$ & $18.543 .610,00$ & 67,01 \\
\hline $\begin{array}{l}\text { Prestaciones locales de servicios gravadas con tarifa diferente de } 0 \% \text { de } \\
\text { IVA }\end{array}$ & $90.556,25$ & 0,33 \\
\hline Ingresos obtenidos bajo la modalidad de comisiones o similares & $244.682,00$ & 0,88 \\
\hline Utilidad en venta de propiedad planta y equipo & $50.000,00$ & 0,18 \\
\hline $\begin{array}{l}\text { Ingresos por reembolsos como intermediario monto total facturado por } \\
\text { operado }\end{array}$ & - & - \\
\hline Otras rentas gravadas & $108.517,91$ & 0,39 \\
\hline Total ingresos & 27.672.685,37 & 100,00 \\
\hline Costo inventario inicial de materia prima & $3.308,00$ & 0,01 \\
\hline Costos compras locales netas materia prima & $78.046,00$ & 0,32 \\
\hline Costo inventario final de materia prima & $2.566,00$ & 0,01 \\
\hline Costo inventario final producto en proceso & 11,00 & 0,00 \\
\hline Inventario inicial bienes no producidos por el sujeto pasivo & $2.505 .827,65$ & 10,39 \\
\hline Costo inventario inicial productos terminados & $1.526,00$ & 0,01 \\
\hline Costo inventario final productos terminados & 590,00 & 0,00 \\
\hline Costo compras locales netas de bienes no producidos por la sociedad & $24.339 .048,00$ & 100,96 \\
\hline
\end{tabular}


Costo de importaciones bienes no producidos por el sujeto pasivo

$757.686,00$

3,14

Costo inventario final bienes no producidos por el sujeto pasivo

$(2.360 .486,00)$

$(9,79)$

Gasto sueldos salarios y demás remuneraciones que constituyen materia gravada del IESS

$926.360,41$

27,73

Gasto beneficios sociales indemnizaciones y otras remuneraciones que no constituyen materia gravada del IESS

$444.869,66$

13,31

Gasto aporte a la seguridad social incluye fondo de reserva

Gastos profesionales honorarios dietas

$162.638,06 \quad 4,87$

Gasto provisiones para desahucio

Gasto otros gastos por beneficios a empleados

$34.119,00$

1,02

$5.570,00$

0,17

Gasto depreciación acumulada de equipos

$27.092,00$

0,81

De activos financieros ( reversión para créditos incobrables)

Gasto por deterioro en el valor de propiedad planta y equipo

Valor no deducible por perdida netas de inventario

$9.546,00$

0,29

$24.992,00$

0,75

$127.007,00$

3,80

Gasto depreciación no acelerada de propiedad planta y equipo

Gasto depreciación acelerada de propiedad planta y equipo

$44.034,79$

1,32

$9.388,00$

0,28

Gasto depreciación del reevaluó de propiedades, planta y equipo

Gasto otras provisiones

$3.252,00$

0,10

$2.779,42$

0,08

Gasto promoción y publicidad

$65.555,09$

1,96

Gasto transporte

$7.754,00$

0,23

$453.773,43$

13,58

Gasto combustibles y lubricantes

$26.294,84$

0,79

Gastos de viaje gasto

$115.836,00$

3,47

Gastos de gestión

$23.780,09$

0,71

Gasto arrendamiento de inmuebles

Gasto suministros y materiales

$96.586,69$

2,89

$29.851,56$

0,89

Gasto mantenimiento y reparaciones

$69.652,50$ 2,08

Valor no deducible mantenimiento y reparaciones

$17.140,00$

0,51

Gasto seguros y reaseguros primas y cesiones

Gasto impuestos contribuciones y otros

$53.571,74$ 1,60

Gasto operaciones de regalías, servicios, Tecnología, Administración No relacionados locales

$19.004,00$

0,57

Gasto servicios públicos

Gasto por siniestros

Valor no deducible impuestos y otros

Gasto comisiones no relacionadas

IVA que se carga al gasto

Gasto servicios públicos

Gasto otros gastos

Costo otros gastos

Gastos no otros operaciones

Valor no deducible otros gastos

23.6

$51.152,00$ 1,53

$11.578,00$ 0,35

$7.664,00$ 0,23

375,00 0,01

$7.148,00$ 0,21

$23.665,91$ 0,71

$88.892,23$ 2,66

$369.120,36$ 11,05

$1.992,00$ 0,06

$1.692,00$ 0,05

$2.170,87$ 0,06

Molina, Luisa; Oña, Jessica; Tipán, Mayra \& Topa, Sharon

Análisis financiero en las empresas comerciales de Ecuador 


\begin{tabular}{lrr}
\hline $\begin{array}{l}\text { Gastos de transacción (comisiones bancarias, honorarios, tasas, entre } \\
\text { otros) }\end{array}$ & $4.602,00$ & 0,14 \\
\hline Gasto interés con instituciones financieras no relacionadas locales & $53.521,00$ & 1,60 \\
\hline Baja de inventarios & $11.407,42$ & 0,34 \\
\hline $\begin{array}{l}\text { Ingresos financieros e interés con instituciones financieros no relaciona- } \\
\text { das locales }\end{array}$ & $2.386,00$ & 0,07 \\
\hline Total costos & $\mathbf{2 4 . 1 0 7 . 6 9 4 , 2 6}$ & 100,00 \\
\hline Total gastos & $\mathbf{3 . 3 4 1 . 1 7 3 , 8 8}$ & 100,00 \\
\hline Total costos y gastos & $\mathbf{2 7 . 4 9 8 . 1 6 8 , 1 4}$ & \\
\hline Saldo del anticipo pendiente de pago antes de rebaja (traslade campo 876 & $\mathbf{3 5 . 8 8 3 , 9 8}$ \\
\hline declaración periodo anterior) & $\mathbf{2 . 0 8 7 , 0 0}$ \\
\hline Perdida del ejercicio & $\mathbf{2 2 8 . 9 4 2 , 2 3}$ \\
\hline Utilidad del ejercicio & $\mathbf{1 7 4 . 5 1 7 , 2 3}$ \\
\hline Utilidad & \\
\hline
\end{tabular}

Fuente: Elaboración propia, a partir de Superintendencia de Compañías (2017)

En base al análisis realizado Estado de más representativos están conformados por los resultados año 2017 del sector comercial, se gastos de beneficios sociales indemnizaciones y puede concluir que los ingresos que más obtiene otras remuneraciones que no constituyen materia este sector está conformado por las ventas netas gravada al IESS, obteniendo una utilidad de locales gravadas con tarifa diferente de 0\% de IVA $\quad \$ 174.517,23$ durante el año 2017.

o exentas del IVA, de la misma manera los gastos

\section{Tabla 2}

\section{Analisis vertical Balance General}

Estado de situación financiera año 2017 del sector comercial Total consolidado Análisis vertical

\begin{tabular}{lcc}
\hline Efectivo y equivalentes al efectivo & $829.697,48$ & 8,79 \\
\hline Cuentas y documentos por cobrar clientes relacionados locales & $3.364 .495,56$ & 35,64 \\
\hline $\begin{array}{l}\text { Otras cuentas y documentos por cobrar corrientes relacionados } \\
\text { locales }\end{array}$ & $160.649,00$ & 1,70 \\
\hline Cuentas y documentos por cobrar clientes no relacionados locales & $1.607 .015,26$ & 17,02 \\
\hline $\begin{array}{l}\text { Otras cuentas y documentos por cobrar clientes no relacionados } \\
\text { locales }\end{array}$ & $8.002,00$ & 0,08 \\
\hline $\begin{array}{l}\text { (-) deterioro acumulado del incobrabilidad (provisiones para cré- } \\
\text { ditos incobrables) }\end{array}$ & $(177.338,13)$ & $(1,88)$ \\
\hline Crédito tributario a favor del sujeto pasivo IVA & $91.293,00$ & 0,97 \\
\hline Crédito tributario a favor del sujeto pasivo por renta & $240.901,45$ & 2,55 \\
\hline
\end{tabular}




\begin{tabular}{|c|c|c|}
\hline Primas de seguro pagadas por anticipado & $6.995,00$ & 0,07 \\
\hline Inventario de productos terminados y mercaderías en almacén & $2.177 .287,00$ & 23,06 \\
\hline Inventario materia prima & $2.566,00$ & 0,03 \\
\hline Inventario en productos en proceso & 11,00 & 0,00 \\
\hline Arrendamiento operativo pagados por anticipado & $1.410,00$ & 0,01 \\
\hline Otros activos por impuestos corrientes & $56.528,73$ & 0,60 \\
\hline Otros pagados por anticipado & $10.542,10$ & 0,11 \\
\hline Otros activos corrientes & $11.863,37$ & 0,13 \\
\hline $\begin{array}{l}\text { (-) deterioro acumulado del valor de inventario por ajuste al valor } \\
\text { neto realizado }\end{array}$ & $51.840,00$ & 0,55 \\
\hline Total activo corriente & $8.443 .758,82$ & 89,44 \\
\hline Otros derechos representativos del capital sociedades & - & - \\
\hline Construcción en curso y otros activos en transito & $16.701,00$ & 0,18 \\
\hline Terrenos ( costo historio antes de expresión o revaluaciones) & $469.975,00$ & 4,98 \\
\hline $\begin{array}{l}\text { Maquinaria y equipo ( costo historio antes de expresión o reva- } \\
\text { luaciones) }\end{array}$ & $127.095,00$ & 1,35 \\
\hline Muebles y enseres & $38.862,92$ & 0,41 \\
\hline Equipo de computación y software & $116.434,00$ & 1,23 \\
\hline Vehículos equipo de transporte y caminero móvil & $295.389,00$ & 3,13 \\
\hline Del costo histórico antes de re expresiones o revaluaciones & $381.871,00$ & 4,04 \\
\hline (-) deterioro acumulado del valor de propiedades, planta y equipo & $(621.180,03)$ & $(6,58)$ \\
\hline Otros activos no corrientes & $86.641,86$ & 0,92 \\
\hline Por contrato de arriendo de equipos de computación & $5.954,00$ & 0,06 \\
\hline Por contrato de arriendo de vehículo & $60.030,00$ & 0,64 \\
\hline Otras propiedades planta y equipo & $19.114,00$ & 0,20 \\
\hline Total activo no corriente & $\mathbf{9 9 6 . 8 8 7 , 7 5}$ & 10,56 \\
\hline Total activo & $9.440 .646,57$ & 100,00 \\
\hline Otras y documentos por pagar corriente no relacionados & $8.219,00$ & 0,11 \\
\hline $\begin{array}{l}\text { Cuentas y documentos por pagar comerciales corriente relacio- } \\
\text { nados locales }\end{array}$ & $2.583 .653,47$ & 35,30 \\
\hline $\begin{array}{l}\text { Cuentas y documentos por pagar comerciales corriente no rela- } \\
\text { cionados del exterior }\end{array}$ & $374.805,00$ & 5,12 \\
\hline $\begin{array}{l}\text { Cuentas y documentos por pagar comerciales corriente no rela- } \\
\text { cionados locales }\end{array}$ & $2.242 .935,48$ & 30,64 \\
\hline Obligaciones con instituciones corriente no relacionados locales & $360.648,00$ & 4,93 \\
\hline $\begin{array}{l}\text { Otros documentos por pagar corrientes a accionistas socios partí- } \\
\text { cipes beneficios u otros }\end{array}$ & $32.361,00$ & 0,44 \\
\hline Obligaciones financieras corrientes no relacionadas locales & $86.484,00$ & 1,18 \\
\hline Obligaciones impuesto a la renta por pagar del ejercicio corriente & $61.195,00$ & 0,84 \\
\hline $\begin{array}{l}\text { Obligaciones participación trabajadores por pagar del ejercicio } \\
\text { corriente }\end{array}$ & $30.304,00$ & 0,41 \\
\hline Obligaciones con el IESS & $62.188,00$ & 0,85 \\
\hline Obligaciones emitidas corriente & $4.815,47$ & 0,07 \\
\hline
\end{tabular}

Molina, Luisa; Oña, Jessica; Tipán, Mayra \& Topa, Sharon 


\begin{tabular}{lcc}
\hline Otros pasivos por beneficios a empleados & $439.339,42$ & 6,00 \\
\hline Otras provisiones corrientes & $246.630,00$ & 3,37 \\
\hline Anticipo clientes & $192.911,00$ & 2,64 \\
\hline Otros pasivos corrientes & $329.584,36$ & 4,50 \\
\hline Total pasivos corrientes & $\mathbf{7 . 0 5 6 . 0 7 3 , 2 0}$ & 96,40 \\
\hline Otras cuentas por pagar no corrientes no relacionados & $92.682,00$ & 1,27 \\
\hline Otros documentos titulares de derechos representativos de capital & $9.845,00$ & 0,13 \\
\hline Cuentas y documentos por pagar comerciales largo plazo relacio- & $133.401,00$ & 1,82 \\
nados locales & & 0,38 \\
\hline Otros pasivos no corrientes otros & $27.706,44$ & 3,60 \\
\hline Total pasivos no corriente & $\mathbf{2 6 3 . 6 3 4 , 4 4}$ & 100,00 \\
\hline Total pasivos & $\mathbf{7 . 3 1 9 . 7 0 7 , 6 4}$ & 3,95 \\
\hline Capital suscrito y/o asignado & $83.800,00$ & 1,55 \\
\hline Aportes del sesiones o accionistas futuras capitalizaciones & $32.815,00$ & 3,25 \\
\hline Reserva legal & $68.862,51$ & 0,94 \\
\hline Reserva facultativa & $19.966,00$ & 2,23 \\
\hline Ganancias netas por reversiones de provisiones por reembolso a & $47.285,00$ & \\
\hline clientes & & 77,01 \\
\hline Utilidad no distribuida ejercicios anteriores & $1.633 .290,00$ & 0,60 \\
\hline Perdida del ejercicio patrimonio & $12.697,00$ & 3,37 \\
\hline Pérdida acumulada ejercicios anteriores & $71.524,82$ & 7,16 \\
\hline Utilidad del ejercicio patrimonio & $151.757,23$ \\
\hline Total patrimonio neto & $\mathbf{2 . 1 2 0 . 9 3 9 , 0 5}$ \\
\hline Total pasivo y patrimonio & $\mathbf{9 . 4 4 0 . 6 4 6 , 6 9}$ \\
\hline
\end{tabular}

Fuente: Elaboración propia, a partir de Superintendencia de Compañías (2017)

Estado de situación financiera año 2017 los pasivos tienen su mayor concentración en la del sector comercial indica que la mayor parte cuenta otros pasivos por beneficios a empleados del pasivo del sector comercial está conformado con un $6 \%$ teniendo una utilidad que representa por Cuentas y documentos por cobrar clientes $7,16 \%$ con un monto de $\$ 151.757,23$.

relacionados locales con un $35,64 \%$ en segundo lugar las cuentas y documentos por pagar comerciales corriente no relacionados locales con un 35,30\% y en tercer lugar la cuenta de (Activo Corriente) / (Pasivo Corriente) = inventario de productos terminados y mercaderías $8.443 .759,00 / 7.056 .073,00=1,20$

en almacén lo que muestra que el estado económico de este sector es óptimo. Por otro lado,

Según la razón corriente en el sector comercial por cada dólar que debe a corto plazo,

REVISTA DE INVESTIGACIÓN SIGMA / Vol. 05, Nº 1, 2018 (pág. 8-28) 
cuenta con $\$ 1,20$ para cumplir sus obligaciones es decir que alcanza a cubrir sus obligaciones a corto plazo y todavía cuenta con 0,20 centavos pero contando con los activos corrientes y los inventarios.

\section{Prueba ácida}

(Activo Corriente - Inventarios) / (Pasivo Corriente) $=$

$(8.443 .759,00-2.179 .864,00) / 7.056 .073,00=$ 0,89

De acuerdo con el resultado las empresas del sector comercial por cada dólar que se adeuda a corto plazo se posee 0,89 centavos para cumplir con sus obligaciones contando solo con los activos corrientes sin considerar los inventarios.

\section{Capital neto de trabajo}

Activo Corriente-Pasivo Corriente

$$
8.443 .759,00-7.056 .073,00=1.387 .686,00
$$

En relación con este cálculo, las empresas comerciales poseen $1.387 .686,00$ millones de capital neto de trabajo. Financieramente la empresa está en un buen punto debido a que, aunque con la prueba ácida no alcanza a cubrir sus obligaciones corrientes aún posee un capital neto de trabajo.

\section{Indicadores de actividad}

\section{Rotación de cartera}

(Cuentas por Cobrar Promedio*365 días) / $($ Ventas a crédito $)=(1.285 .040,50 * 365) /$ 3.364.496,00 = 139,41 días

El resultado obtenido indica que las entidades tardan 130, 42 aproximadamente 131 días en cobrar a sus clientes lo que significa que poseen una rotación de cartera lenta lo que no es bueno para las entidades porque no se trata de empresas manufactureras y necesitan de efectivo para sus operaciones.

\section{Rotación de inventario}

(Inventario Promedio*365)/(Costo de Mercancía Vendida $)=(726.621,33 * 365) / 24.107 .694,00$ $=11$ días

La empresa tarda 11 días en convertir sus inventarios en efectivo o cuentas por cobrar, además es una rotación ágil porque tarda menos de 30 días lo que es conveniente para la empresa.

\section{Rotación de proveedores}

(Cuentas por Pagarpromedio*365días)

$($ Compras Totales $)=(78.642,67 * 365)$

$133.401,00=215,18$

Las empresas comerciales tardan 215,18

Molina, Luisa; Oña, Jessica; Tipán, Mayra \& Topa, Sharon 
días aproximadamente 216 días en cancelar sus obligaciones implica una rotación de proveedores debido a que tarda más de 30 días pero considerando que es un amplio número de empresa es un término aceptable.

\section{Ciclo efectivo}

(Rotación de Cartera+Rotación de Inventarios totales)-Rotación de Proveedores

$$
139,41+11,00-215,18=(64,77)
$$

Las empresas comerciales están en un cierto problema puesto que un ciclo efectivo resulta negativo aproximadamente 67 días. Lo que quiere decir que como la rotación de inventarios es ágil y la rotación de cartera es lenta no puede cubrir a tiempo sus deudas con los proveedores y por ende paraliza sus operaciones.

\section{Rotación del activo}

Ventas $/($ Activos Totales $)=27.361 .488,00 /$

$$
4.720 .323,50=5,80
$$

Los activos totales de las entidades comerciales rotaron 5,80 veces al año se puede explicar que por cada dólar invertido en activos la empresa genera ventas de 5,8 lo que nos muestra que los activos si son importantes para generar ventas en las empresas.

\section{Indicadores de rentabilidad}

\section{Margen bruto}

margen bruto $=($ beneficio bruto $) /$ ventas $=$ $228.942,00 / 27.361 .488,00=0,01$

Los resultados obtenidos manifiestan que por cada dólar vendido se obtiene un $1 \%$ de utilidad bruta descontando solo el costo de mercadería vendida.

\section{Margen operacional de utilidad}

margen operacional de utilidad = (utilidad operacional) / (ventas netas) = $228.942,00 / 27.361 .488,00=0,00836$

Los resultados obtenidos manifiestan que por cada dólar vendido se obtiene un $0,84 \%$ de utilidad operacional descontando no solo el costo de mercadería vendida sino otros gastos.

\section{Rendimiento del patrimonio (ROE)}

ROE $=$ (beneficio neto) $/($ fondos propios $)=$ $228.942,00 / 2.120 .939,00=0,108$

Las empresas comerciales obtienen $10,8 \%$ con respecto al activo total, es decir que por cada dólar invertido se genera 10,8 centavos de utilidad neta del periodo.

\section{Rendimiento del Activo Total (ROA)}


ROA $=($ EBIT-impuestos $) /($ activos totales $)=$

$($ beneficio neto + intereses $) /($ activos totales $)=$

$228.942,00 \quad / 4.720 .323,50=0,05$

Las empresas comerciales tienen un rendimiento del activo es decir un ROA del $5 \%$ sobre los activos totales es decir los activos ayudan a la generación de utilidades

\section{Ebitda}

EBITDA $=$ utilidad operacional + gastos por depreciación + gastos por amortización $=$ $228.942,00+9.546,00=238.488,00$

El margen de EBITDA dentro de las entidades comerciales de $\$ 238.488,00$, lo que quiere decir que las ventas contribuyen a las utilidades restando las depreciaciones.

\section{Indicadores de endeudamiento}

Nivel de Endeudamiento

Nivel de endeudamiento $=($ Total Pasivo $) /($ Total Activo $)=7319707,64 / 9.440 .646,57=0,7753$

En el análisis del nivel de endeudamiento se establece que los acreedores son dueños del $77,53 \%$ mientras que los accionistas tan solo poseen el $22,47 \%$, al tratarse del sector comercial no es factible.

\section{Concentración de pasivo a corto plazo}

concentración de pasivo en el corto plazo= (Pasivo Corriente) / (Pasivo Total) $=$ $7.056 .073,20 / 9.440 .646,57=0,7774$

Este resultado indica que se tiene un $77,74 \%$ en el pasivo a corto plazo del total de pasivos lo que no es conveniente porque no se podrá alcanzar a cubrir sus obligaciones en el tiempo establecido.

\section{Endeudamiento Financiero}

Endeudamiento financiero $=$ (Obligaciones financieras promedio $) /($ ventas $)=86.484,00 /$ $27.361 .488,00=0,003087$

Las empresas del sector comercial actualmente no cuentan con endeudamiento con instituciones financieras muy significativas debido a que corresponde al 0,31\%.

\section{Impacto de la carga financiera}

Impacto de la carga financiera $=$ (Gastos financieros $) /($ ventas $)=53.521,00 / 27.361 .488,00$ $=0,001433$

Los gastos financieros representan el $0,14 \%$, es decir que de las ventas hay que destinar el $0,14 \%$ cada año para pagar gastos por intereses financieros.

Molina, Luisa; Oña, Jessica; Tipán, Mayra \& Topa, Sharon 


\section{Cobertura de intereses I}

Cobertura de intereses $I=($ Utilidad $\mathrm{de}$ operación $) /($ Gastos financieros $)=228.942,00 /$ $53.521,00=4,28$

Según el porcentaje determinado no es factible que las empresas del sector comercial soliciten prestamos debido a que están al límite de la capacidad de endeudamiento

\section{Cobertura de intereses II}

Cobertura de intereses II $=($ EDITDA $) /($ Gastos financieros $)=238.488,00 / 53.521,00=4,45$

Según el porcentaje determinado no es factible que las empresas del sector comercial soliciten prestamos debido a que están al límite de la capacidad de endeudamiento esto sin contar con las depreciaciones y amortizaciones es decir considerando la utilidad operacional

\section{Conclusiones}

El análisis financiero y los indicadores financieros como es el de liquidez, actividad, endeudamiento y rentabilidad son muy importante dentro de todo tipo de entidad puesto que es considerado como una herramienta clave para conocer el estado real de las entidades y poder tomar decisiones correctas a favor de la entidad para que así no tenga problema al cumplir sus objetivos organizacionales.

Dentro de las empresas comerciales el Estado de situación financiera año 2017 del sector comercial indica que la mayor parte del pasivo del sector comercial está conformado por Cuentas y documentos por cobrar clientes relacionados locales con un $35,64 \%$. En base al análisis realizado Estado de resultados año 2017 del sector comercial, se puede concluir que los ingresos que más obtiene este sector está conformado por las ventas netas locales gravadas con tarifa diferente de $0 \%$ de IVA o exentas del IVA, de la misma manera los gastos más representativos esta conformador por los gastos de beneficios sociales indemnizaciones y otras remuneraciones que no constituyen materia gravada del IESS, obteniendo una utilidad de \$174.517,23 durante el año 2017.

Se puede concluir que el sector comercial del Ecuador acumulo activos por $\$ 9440646,57$ millones conformado por $\$ 9440646,57$ del activo corriente, $\$ 996887,75$ del activo no corriente, por otro lado acumulo en los pasivos por $\$ 7319707,64$ conformado por $\$ 7056073,2$ de pasivo corriente y $\$ 263634,44$ del pasivo no corriente obteniendo como patrimonio un total del sector comercial de \$2120939,05. 


\section{Referencias bibliográficas}

Álvarez, K. \& Morocho, S. (2013) análisis financiero de una estación de servicio local y su impacto en el crecimiento de la empresa. Universidad de Cuenca. (p.3335) Obtenido de http://dspace.ucuenca. edu.ec/bitstream/123456789/3538/1/ TESIS.pdf

Aponte, H. \& Cuello, G. (2018). Diagnóstico financiero estratégico para la empresa BIOMAX S.A. Recuperado de https:// repository.eafit.edu.co/bitstream/ handle/10784/12596/Hollman_Aponte_ Gabriel_Cuello_2018.pdf? sequence $=2$

Barrios, C.; Huamán, G. \& Rodríguez, J. (2016). Influencia de las ratios financieras en la toma de decisiones de la empresa architech constructores S.A.C. Universidad Peruana de las Américas. (pp. 25-26). Obtenido de http://repositorio.ulasamericas.edu. pe/bitstream/handle/upa/153/tesis\%20 -capitulo\%20\%28BN\%29\%20Edita. pdf?sequence $=1$ \&isAllowed $=\mathrm{y}$

Bravo, J. (2017). Factores que afectan la sostenibilidad y el crecimiento de las pequeñas empresas en la ciudad de Bucaramanga - Santander - Colombia. Revista de investigación SIGMA. Vol.4 (2017), pp. 66-67 Recuperado de https:// journal.espe.edu.ec/ojs/index.php/Sigma/ article/view/65-81/pdf

Castaño, A \& Giraldo, Y. (2012). Indicadores de endeudamiento. Recuperado de https://ticsycomunicacion.files. wordpress.com/2012/11/indicadores-de- endeudamiento.pdf

Castelo, O. \& Anchundia, A. (2016) estrategias para la administración del capital de trabajo en la empresa editmedios s.a. Universidad de Guayaquil. (pp. 72-73). Recuperado de http://repositorio.ug.edu. ec/bitstream/redug/11106/1/TESIS\%20 FINAL.pdf

Castillo, Y. (2012). Evaluación financiera de liquidez en las empresas distribuidoras de productos farmacéuticos a través del ciclo de conversión de efectivo. Universidad de San Carlos de Guatemala. (pp. 36-37). Recuperado de http://biblioteca.usac.edu. gt/tesis/03/03_4031.pdf

Cárdenas, J. (2016). Análisis diagnóstico y propuesta de mejora administrativa y financiera para una pequeña empresa de la industria metal mecánica en la cuidad de san Luis potosí. Universidad Autónoma de San Luis de Potosí. (pp.3738). Obtenido de http://ninive.uaslp.mx/ jspui/bitstream $/ \mathrm{i} / 4156 / 1 /$ Tesis $\% 20 \% 20$ Jorge $\% 20 \mathrm{Ca} \% \mathrm{CC} \% 81$ rdenas.pdf

Ciappa, M. (2005). Indicadores de rentabilidad en el sector agrario argentino. Buenos Aires: Federación de Centro y Entidades de Acopiadores de Cereales, Facultad de Ciencias Económicas Universidad Nacional de Plata. Recuperado de http:// producirconservando.org.ar/intercambio/ docs/rentabilidad_sector_agrario_ argentino.pdf

De La Hoz Suárez, B.; Ferrer, M. \& De La Hoz Suárez, A. (2008). Indicadores de

Molina, Luisa; Oña, Jessica; Tipán, Mayra \& Topa, Sharon 
rentabilidad: herramientas para la toma decisiones financieras en hoteles de categoría media ubicados en Maracaibo. Revista de Ciencias Sociales, 14(1), 88109.

Fontalvo Herrera, T.; Mendoza Mendoza, A. \& Morelos Gómez, J. (2011). Evaluación del impacto de los sistemas de gestión de la calidad en la liquidez y rentabilidad de las empresas de la Zona Industrial de Mamonal (Cartagena-Colombia). Revista Virtual Universidad Católica del Norte, (34).

Garzón, M. (2017). Análisis de sostenibilidad, rentabilidad y endeudamiento de SkyNey de Colombia S.A.S a través de indicadores financieros. Recuperado de https://repository.ucatolica. edu.co/bitstream/10983/14483/1/ A n \% C 3\% A 11 is is \% 20 de $\% 20$ Rentabilidad\%2C\%20Liquidez\%20 y $\% 20$ Endeudamiento $\% 20$ de $\% 20$ SkyNet\%20de\%20Colombia\%20-\%20 Mariana\%20 Garz\%C 3\%B3n\%20 Gonz\%C3\%A1le.pdf

Jaramillo, M. \& Cardenas-Perez, A. (2018). Modelizacion econometrica bajo la metodologia de box-jenkins. estudio empirico a la liquidez del sistema financiero ecuatoriano. Investigación Operacional, 39(4), 592-607.

Méndez, C. (2007). EBITDA, ¿es un indicador financiero contable de agregación de valor?. CAPIC REVIEW, (5), 4.

Pérez, J. (2014). Incidencia de la morosidad de cartera en la sostenibilidad financiera de la E.S.E Hospital Emiro Quintero Cañizares, Durante el periodo 2010_2012. Universidad Francisco de Paula Santander Ocaña. (pp.3233). Recuperado de http://repositorio. ufpso.edu.co:8080/dspaceufpso/ bitstream/123456789/231/1/25188.pdf

Pineda, F. \& Piñeros-Gordo, J. (2009). El indicador financiero único como mecanismo de alerta temprana: una nueva versión. Temas de Estabilidad Financiera; No. 39.

Quizhpe, P. (2013). Propuesta de mejoramiento para la empresa comercial aceros del sur cía. De la cuidad de Loja. Universidad de Loja. (pp. 24-30). Recuperado de http://dspace.unl.edu.ec/jspui/ bitstream/123456789/2143/1/2.\%20 TESIS\%20DE\%20GRADO\%20.pdf

Reyes, I.; Cadena, L. \& León, I. (2014). La importancia del análisis de los estados financieros en la toma decisiones. Universidad Autónoma del Estado de Hidalgo (pp.24-25). Recuperado de https://www.uaeh.edu.mx/scige/boletin/ tlahuelilpan/n4/e2.html

Tárraga,A. (2011). Uso de indicadores financieros para evaluar el impacto de las Prácticas de Alta Implicación. WPOM, 2(2), 32-43. 